\title{
Governança global: visões teóricas e pluralidade de atores ${ }^{1}$
}

\author{
Global governance: theoretical views and plurality of actors
}

\section{Gobernanza global: visiones teóricas y pluralidad de actores}

\author{
Juliano Oliveira Pizarro ${ }^{2}$, Carmen Silvia de Moraes Rial ${ }^{3}$
}

Resumo: A presente pesquisa tem o objetivo de fazer uma análise teórica sobre o movimento da governança global, através do estudo dos principais atores, articulações e mecanismos alternativos. A metodologia utilizada no trabalho foi revisão bibliográfica de abordagem qualitativa. Teve-se como critério a utilização de literatura clássica, artigos, estudos contemporâneos sobre a temática. A delimitação temporal da pesquisa se deu a partir da década de 1990, devido à ascensão dos processos de globalização após a guerra-fria, da nova ordem multipolar e do recrudescimento do neoliberalismo. Ocorreram assim mudanças nos paradigmas internacionais das relações políticas e econômicas entre atores heterogêneos e plurais -Estados nacionais, empresas multinacionais, sociedade civil global, organizações internacionais, blocos regionais-. Isso ampliou os cenários e espaços de disputa pelo poder. Essas dinâmicas comportam uma pluralidade de atores públicos e privados que disputam espaço e relacionam-se ao mesmo tempo. É nesse cenário de disputa, controle e condução pelo poder que as dinâmicas da governança global são estabelecidas, sem necessariamente um governo mundial constituído e revestido de uma única autoridade. O caráter contraditório e por vezes não explícito da governança global tem apresentado desafios teóricos para qualquer tentativa de entender seu funcionamento e sua evolução.

Palavras-chave: Governança Global. Teorias. Pluralidade. Atores.

\footnotetext{
${ }^{1}$ Recibido: 27/08/2017. Aceptado: 16/03/2018

${ }^{2}$ Doutorando pelo Programa de Pós-Graduação Interdisciplinar em Ciências Humanas da Universidade Federal de Santa Catarina, mestre em Ciência Política pelo Programa de Pós-Graduação em Ciência Política da Universidade Federal de Pelotas, bacharel em Direito pela Universidade Federal de Pelotas e graduando em Educação Física Licenciatura pelo Centro Universitário Claretiano. Realizou tutoria presencial de Inglês pela Rede e-Tec/IFSUL (Campus CAVG), estágio no Serviço de Assistência Judiciária da UFPel e monitoria de Direito Internacional Público - Programa Institucional de Bolsas de Iniciação Científica (PIBIC). Realiza pesquisas nas áreas de esporte e teoria política internacional, com enfoque nas temáticas sobre governança global, soft power, decolonialidade latino-americana, futebol e economia política. E-mail: jopizarro@hotmail.com

${ }^{3}$ Jornalista e antropóloga. Doutora em Antropologie et Sociologie pela Université de Paris V. Professora Titular do Departamento de Antropologia da UFSC (1982), atua no Programa de Pós-Graduação em Antropologia Social e no Doutorado Interdisciplinar em Ciências Humanas, os quais coordenou. Realizou pósdoutorado no Laboratoire dAnthropologie Sociale (Collège de France/CNRS), na École dês Hautes Études en Science Sociale (EHESS) e na Univesité de Toulouse. Participou da criação das revistas Ilha, Vibrant, Novos Debates e da TV ABA e integra mais de 20 conselhos Atualmente, é vice-Presidente do Conselho Mundial de Associações Antropológicas (WCAA), representante da Comissão de Antropologia Urbana da IUAES na América Latina e coordenadora do PPGICH. Email: rial@cfh.ufsc.br
} 
Abstract: The objective of this research is to carry out a theoretical analysis of the global governance movement through the study of the main actors, articulations and alternative mechanisms. The methodology used in the study was a bibliographical review of a qualitative approach. The criteria included the use of classical literature, articles and contemporary studies on the subject. The temporal delimitation of the research began in the 1990s, due to the rise of globalization processes after the Cold War, with the new multipolar order and the resurgence of neo-liberalism. So many changes occurred in international paradigms of political and economic relations between heterogeneous actors and plurals - nation states, multinational corporations, global civil society, international organizations, regional blocks - that the scenarios and spaces of power struggle expanded. These dynamics involve a plurality of public and private actors competing for space and relating at the same time. It is in this scenario that dispute for and control of the power dynamics of global governance are established, without necessarily a single world government anointed with authority. The contradictory, and sometimes not explicit, character of global governance has presented theoretical challenges for any attempts to understand its operation and its evolution.

Keywords: Global Governance. Theories. Plurality. Actors.

Resumen: la presente investigación tiene como objetivo hacer un análisis teórico sobre el movimiento de la gobernanza global a través del estudio de los principales actores, articulaciones y mecanismos alternativos. La metodología utilizada en el trabajo fue revisión bibliográfica de abordaje cualitativa. Se tuvo como criterio la utilización de literatura clásica, artículos, estudios contemporáneos sobre la temática. La delimitación temporal de la investigación se dio a partir de la década de 1990, debido al acenso de los procesos de globalización después de la guerra fría, al nuevo orden multipolar y al recrudecimiento del neoliberalismo. Ocurrieron de esta forma cambios en los paradigmas internacionales de las relaciones políticas y económicas entre actores heterogéneos y plurales -Estados nacionales, empresas multinacionales, sociedad civil global, organizaciones internacionales, bloques regionales.- Eso amplió los escenarios y espacios de disputa por el poder. Esas dinámicas comprenden una pluralidad de actores públicos y privados que disputan espacio y se relacionan al mismo tiempo. Es en ese escenario de disputa, control y conducción por el poder que las dinámicas de la gobernanza global son establecidas, sin necesariamente un gobierno mundial constituido y revestido de una única autoridad. El carácter contradictorio y muchas veces no explícito de gobernanza global ha presentado desafíos teóricos para cualquier intento de entender su funcionamiento y evolución.

Keywords: Global Governance. Theories. Plurality. Actors.

\section{Introdução}

O surgimento das teorias sobre governança global ocorreu principalmente a partir do início da década de 1990, após a queda do muro de Berlim, diante dessa ordem agora multipolar que rearticulou os centros de autoridade global. Essas dinâmicas comportam uma pluralidade de atores públicos e privados que disputam espaço e relacionam-se ao mesmo tempo. É nesse campo de disputa, controle e condução pelo poder que as dinâmicas da governança global são estabelecidas, sem necessariamente 
um governo mundial constituído e revestido de uma única autoridade. Em relação ao processo de globalização, pode-se afirmar que o mesmo não é homogêneo; pelo contrário, há vários atores atuando no cenário global, caracterizando um processo de globalização econômica, política e cultural que obedece a ritmos e lógicas distintas em cada uma dessas esferas (Avritzer, 2002, p. 112).

Diante desse cenário, a pesquisa tem o objetivo de fazer uma análise teórica sobre o movimento da governança global, através do estudo dos principais atores, articulações e mecanismos alternativos. A metodologia utilizada no trabalho foi revisão bibliográfica de abordagem qualitativa. Teve-se como critério a utilização de literatura clássica, artigos, estudos contemporâneos sobre a temática. O termo Governança, no início da década de 1990, passou a ser utilizado por instituições como a Organização das Nações Unidas (ONU), Fundo Monetário Internacional (FMI) e Banco Mundial (BM). Trata-se de um conceito muito geral que pode ser aplicado aos diferentes tipos de organizações.

Assim, pode ser definida e associada a um tipo de organização ou área específica, por exemplo: governança pública, governança global, governança corporativa, governança desportiva, dentre outras. Nesse sentido, Governança não se restringe aos aspectos gerenciais e administrativos do Estado, tampouco ao funcionamento eficaz da máquina pública (Santos, 1997, p. 341). O termo pode ser usado não só para descrever esses diversos temas, mas também para definir agendas normativas ou práticas.

A governança é a forma como as regras e ações são produzidas, sustentadas e reguladas, tendo como princípios de "boa governança" critérios como transparência, responsabilidade, liderança, integridade, compromisso, integração, efetividade e accountability (Marques, 2007, p. 19-20). O termo refere-se também a padrões de articulação e cooperação entre atores sociais e políticos, bem como arranjos institucionais que coordenam e regulam transações dentro e através das fronteiras do sistema econômico. Inclui-se no conceito não apenas os mecanismos tradicionais de representação, tais como os partidos políticos e grupos de pressão, como também redes sociais informais, hierarquias e associações de diversos tipos (Santos, 1997, p. 342).

Assim, o contexto da chamada governança global, a qual tem sido amplamente associada com a figura do "governo", associa-se com a autoridade política e/ou instituições no interior do sistema internacional. Como já introduzido, governança denota instituições políticas formais que visam coordenar e controlar as práticas do governo e que têm a capacidade de impor as suas decisões. Rosenau (2000) utilizou de forma pioneira a ideia de "governança" para explicar o funcionamento das relações interdependentes na ausência de uma autoridade política global, nos primórdios dos anos 1990.

A rápida disseminação do conceito parece refletir a consciência de uma mudança de paradigma nas relações de poder. Foi percebida a inadequação do conceito clássico de "governo" para descrever as mudanças que ocorreram no contexto da globalização. Com o aumento de atores transnacionais, como empresas multinacionais, ONGs, dentre outros, houve uma intensificação da atuação desses atores a nível local e global, e os governos nacionais passaram de referência central da organização política a um dos atores nesse cenário. $O$ caráter contraditório e por vezes não explícito da governança global tem apresentado desafios teóricos para o entendimento de seu funcionamento e evolução. 


\section{Governança global: questões conceituais, políticas e operacio- nais}

O conceito e a prática da soberania têm desempenhado um papel fundamental no estudo dos assuntos internacionais, particularmente no caso das Relações Internacionais. Teóricos da área têm o Estado como um ator internacional que tem sido objeto fundamental de estudo, mudanças de concepções e práticas de soberania estatal têm estimulado uma revisão completa das teorias prevalecentes. A construção do conceito prático de soberania está dentro das correntes de pensamento mais influentes na teorização sobre as relações internacionais: realistas e liberais em suas versões tradicionais e "neo". Então, ele se aproxima dos exercícios de desconstrução da soberania das abordagens crítica e pós-moderna. Finalmente, sua reconstrução é proposta a partir dos postulados do construtivismo social (Cardozo de da Silva, 2007, p. 180).

Nesta perspectiva, para esclarecer as diferentes dimensões da soberania, uma proposta de Stephen Krasner (1999) repensa a questão da soberania ao reconhecer quatro dimensões importantes para o conceito. A primeira delas é a chamada 'soberania westfaliana', na qual há independência de outros estados que permanecem excluídos dos processos domésticos. A segunda é o direito de soberania internacional e reconhecimento recíproco de estados como legalmente iguais. Há ainda, a chamada 'soberania doméstica', poder da própria organização governamental dentro do estado (autodeterminação). Por fim, há a 'soberania da interdependência' e a capacidade de controle sobre os fluxos transfronteiriços (Krasner, 1999). Os dois primeiros conceitos estão associados com autoridade e legitimidade, mas não com controle, o terceiro com ambas as esferas e o quarto unicamente ao controle.

Krasner demonstra a complexidade de se desconstruir o conceito de soberania e suas ligações com o Estado. O autor traz o conceito de hipocrisia organizada que, conforme a lógica de consequências, se une com a corrente realista das relações internacionais. Assim como Morgenthau (2003), o autor vê o sistema internacional como sendo anárquico, prevalecendo a política do poder e a sua distribuição assimétrica. Desse modo, chega-se a necessidade de entender o conceito de governança global.

A partir de uma ampla revisão da literatura sobre o tema, Ballestrin (2010, p. 105108) constatou que McGrew aponta uma ideia de governança global com clara inspiração liberal-internacionalista democrática, encontrada no relatório da chamada "Nossa Comunidade Global", elaborada pela Comissão sobre Governança Global (1996). A denominada comissão trouxe o conceito de governança global tal como pensado abaixo:

Governança é a totalidade das diversas maneiras pelas quais os indivíduos e as instituições, públicas e privadas, administram seus problemas comuns. É um processo contínuo pelo qual é possível acomodar interesses conflitantes ou diferentes e realizar ações cooperativas. Governança diz respeito não só a instituições e regimes formais autorizados a impor a obediência, mas também a acordos informais que atendam aos interesses das pessoas e instituições.

A chamada "boa governança" é considerada aquele que presta contas, eficiente, legítima, representativa e transparente. A partir dela, torna-se um modelo a ser seguido pelos países que recebem sua assistência e parâmetro também para as agências econômicas internacionais. Com isso, foram criados índices para apontar o grau de democracia, 
accountability, eficiência, desenvolvimento sustentável, sustentabilidade, cooperação, responsabilidade social, capital social e participação da sociedade civil, a fim de atrelar a boa governança econômica com componentes cívicos e humanos.

O conceito de governança global traz a ideia de que o Estado não é o único ator no cenário internacional. Portanto, as organizações, regimes e instituições internacionais multilaterais e atores privados surgiram com força, fazendo com que ocorra o que Rosenau (2000, p.13) chama de um deslocamento contínuo e uma rearticulação dos centros de autoridade. Esse é um fenômeno complexo, o qual implica fragmentação, desagregação, inovação, e, sobretudo, em uma realocação de autoridade, suscitando um questionamento crítico sobre a orientação de ações espontâneas sob o emblema da cooperação.

A partir de então, surge o cenário da governança global. Diferenciam os teóricos que a consideram um fenômeno empiricamente observável, daqueles que a subscrevem como um programa político, de sorte que os estudos sobre o tema costumam sobrepor ordens analíticas e normativas (Rosenau, 2000, p. 21-22).

A autora traz a definição de Keohane, a qual governança pode ser definida como a elaboração e aplicação das regras e o exercício do poder dentro de um determinado domínio de atividade. A governança global refere-se à tomada de poder e ao exercício deste em uma escala global, mas não necessariamente por organismos autorizados, envolvendo interações estratégicas entre entidades que não estão dispostos em hierarquias formais.

Aliado a isso, ela aponta o pensamento de Finkelstein, no qual diz que o termo 'governança' é assim chamado por não se entender o que estava (e ainda está) acontecendo. Naquele momento, a ideia remetia a um modus operandi em curso aparentemente horizontal, descentralizado e não hierárquico. A partir dessa ideia antagônica, passou-se a questionar qual seria a intencionalidade dos atores que conduziam essa chamada governança global, que diziam que a mesma estava diluída na ideia de um poder coletivo descentrado e consensual, o que camuflava novas formas de dominação.

Desta forma, Ballestrin traz o pensamento de Cox, o qual apontou que existem meandros nebulosos na governança global, pois seria uma nuvem de influências ideológicas que alimentam o pensamento da elite às necessidades do mercado mundial. A não regulação seria precisamente uma estratégia de hegemonia global e a governança global a guia política da globalização neoliberal hegemônica.

Essa governança "sem governo" é a concepção utilizada nesse presente trabalho como pressuposto do ambiente ao qual o objeto de estudo está inserido como ator, exatamente por ela possuir uma série de atores no exercício de poder em uma escala global, onde não necessariamente essas entidades são autorizadas a agir por um consentimento geral. No entanto, alguns desses atores acabam ganhando força nesse cenário internacional, principalmente organizações internacionais não governamentais.

A governança global contemporânea é caracterizada por um elevado grau de diversidade e complexidade. Os arranjos de governança podem tomar formas públicas, privadas ou híbridas. Além de refletir o desejo de não criar e capacitar entidades independentes, eles podem envolver muitos dos intervenientes no processo de tomada de decisão ou de transmitir o poder esmagador de alguns (Koenig-Archibugi, 2003, p. 15).

Como foi observado, o termo governança global tem sido utilizado para definir o conjunto de instituições formais e informais, mecanismos, relações e processos entre e dentre os estados, mercados, cidadãos e organizações, tanto internacionais e não gover- 
namentais, no sentido de se atribuir uma regulamentação para demandas em escala global. Em tese, visa atingir interesses coletivos no plano global, tendo em vista atribuir direitos e obrigações para os atores no plano internacional e a mediar conflitos. Rosenau (2000, p. 19) aponta o conceito da regulação das relações interdependentes exatamente nessa ausência de uma autoridade política global. O melhor exemplo disso é o sistema internacional ou as relações entre Estados independentes. Contudo, o Estado não é o único ator, sendo importante observar os atores envolvidos nesse cenário global.

De acordo com Santos (2002):

Uma análise mais aprofundada dos traços dominantes da globalização política - que são, de facto, os traços da globalização política dominante - leva-nos a concluir que subjazem a esta três componentes do Consenso de Washington: o consenso do Estado fraco; o consenso da democracia liberal; o consenso do primado do direito e do sistema judicial.

Ballestrin ainda observa que recentemente a noção de uma "comunidade internacional" foi desenvolvida para se referir a um grupo de Estados que estabeleceram regras, processos e instituições no âmbito internacional. Desta forma, as demandas têm sido estabelecidas pelo direito internacional, pela diplomacia e pelos organismos supra estatais. Porém, mesmo com a globalização e os novos atores que vem surgindo nesse cenário internacional, o Estado mantém três aspectos muito importante: apenas o Estado pode estabelecer leis dentro de seu território para os que nele vivem, o Estado assegura uma identidade nacional única e, além disso, o Estado mantém o monopólio do poder coercitivo - na esfera interna com suas forças de policiamento e com suas forças armadas na externa.

No panorama das relações internacionais, a soberania de um Estado está condicionada ao reconhecimento diplomático ${ }^{4}$ dos demais. Entende-se que um Estado pode vir a reconhecer outro a partir do estabelecimento de relações diplomáticas entre ambos, pois presume-se que há um reconhecimento internacional mútuo. No entanto, quando ocorre a ruptura das relações diplomáticas não envolve, em geral, nenhuma perda de reconhecimento. Da mesma forma, uma declaração formal e simples também é válida para reconhecer outro Estado, apesar de não estabelecer relações diplomáticas.

A partir disso, pode-se observar que atualmente o reconhecimento de Estados soberanos ocorre através de um ritual de incorporação à Organização das Nações Unidas, ou seja, através de uma organização internacional (Herz, Hoffmann, 2004). Contudo, esses fatores não apontam necessariamente para um enfraquecimento da figura do Estado, pois como observa Villa (2001, p. 70) há temas cuja regulação internacional, por um lado, possui menor disparidade na capacidade de controle pelos Estados mais poderosos e, por outro lado, maiores possibilidades de ação por parte dos atores não estatais. A unidade política estatal permanece, contudo, o eixo principal de decisão nos processos globais (Villa, 2001, p. 73).

\footnotetext{
${ }^{4}$ Em relação a definição para o reconhecimento, as Convenções sobre direitos e deveres dos Estados e sobre asilo político (Convenção de Montevidéu) dispõe:

"Artigo 1: O Estado como pessoa de Direito Internacional deve reunir os seguintes requisitos.

I. População permanente.

II. Território determinado.

III. Governo.

IV. Capacidade de entrar em relações com os demais Estados" (BRASIL, 2015).
} 
David Held (1995) nos diz que a interconectividade regional e global contesta as tradicionais soluções nacionais para os problemas-chave da democracia teórica e prática. A questão da governança ultrapassa a noção de Estado Nação, pois decisões nacionais econômicas, ambientais, bélicas, tecnológicas de uma nação (que a princípio se limitariam ao exercício da sua soberania), podem causar impactos em nações vizinhas. Além disso, num contexto de interconectividade global outras questões sobre viabilidade, coerência e responsabilidade das decisões nacionais devem ser globalmente consideradas.

No início do século XXI, se vive em uma sociedade mundial de pleno direito, composta por um sistema global de Estados, organizações mundiais, meios de comunicação de alcance global, mercados mundiais, política mundial e problemas que afetam igualmente a todos em todo o mundo (Brunkhorst, 2011). Com isso, surgem novas formas de governança global e de estruturas jurídicas transnacionais. A questão para a política é como incutir esse processo com legitimidade democrática. Questiona-se se é possível haver e de que forma se dariam práticas democráticas para participar na constituição dessa chamada governança global. Também se questiona a capacidade coletiva de orientar as instituições sociais, políticas e econômicas que afetam a sociedade em uma escala transnacional. A democracia cosmopolita, o regionalismo democrático e uma governança democrática representam três formas de política nessa busca (Lupel, 2003, p. 29).

O cosmopolitismo surge com um discurso importante e otimista, visando à igualdade, à proteção aos direitos humanos e o diálogo como forma mais eficaz para consolidação do estado de paz. Villa e Tostes (2006, p. 95) apontam que:

Os teóricos da democracia cosmopolita têm chamado a atenção para o fato de que os desdobramentos tecnológicos, econômicos e culturais da globalização redimensionam as funções do Estado, funções essas que se deslocam para outras instituições e minam a soberania estatal, mas de outro lado também geram políticas de solidariedade entre movimentos sociais e outros grupos de pressão como ONGs.

Ocorre, assim, a criação de organismos supra estatais no novo cenário das relações internacionais. Diversos tipos de organizações nas mais variadas áreas, com finalidades que abrangem assuntos locais, regionais e globais, com estrutura e organização para exercer atividades e metas próprias.

De acordo com Ramos (2011, p. 14):

Definidas como "a forma mais institucionalizada de realizar a cooperação internacional", as organizações internacionais - divididas, de maneira geral, em Organizações Intergovernamentais Internacionais (OIGs) e Organizações Não Governamentais Internacionais (ONGIs) - têm adquirido mais importância no cenário mundial à medida que conceitos como interdependência, governança global, multilateralismo, regimes internacionais e o próprio direito internacional - aos quais daremos mais atenção mais adiante - são mais aceitos, institucionalizados e utilizados como mecanismos de estabilização do sistema internacional.

Nesse aspecto, pode-se observar que regimes internacionais estabelecidos podem vir a resultar na criação de novas organizações ou novos conjuntos de organizações internacionais, tendo em vista que já reúnem algumas das ferramentas culturais e institucionais necessárias. Como exemplo, Krasner, Keohane e Nye são autores que atribuem 
aos regimes internacionais papel fundamental no plano internacional (Ramos, 2011, p. 21). Diante disso, visando articulações com base na cooperação nos mais variados setores, criam-se organizações internacionais, sujeitos de direito internacional público, regidos por um conjunto de regras próprias através de membros associados. Via de regra, o conceito é normalmente utilizado para definir as organizações intergovernamentais, como a ONU, Organização Mundial do Comércio (OMC), Organização Mundial da Saúde (OMS), assim como blocos regionais como União Europeia (UE), MERCOSUL (Mercado Comum do Sul), dentre outros, cujos membros são entes estatais.

No que tange ao surgimento de novos atores institucionais no cenário internacional, (Jenks, 2015, p. 227) afirma que:

En la última década se ha constatado el surgimiento de una vasta gama de nuevos actores institucionales. Entre ellos se incluyen actores del nivel intergubernamental, por ejemplo, el G20 y los BRICS. Estos agrupamientos han elaborado importantes agendas y funciones de formulación de políticas para toda una serie de cuestiones relacionadas con el desarrollo. Asimismo, ha habido un crecimiento significativo en el campo de acción de los órganos y las alianzas regionales.

Rozine de Abreu (2004, p. 3) define que mecanismos de caráter multilateral, as organizações internacionais são definidas como arranjos formais, transcendendo as fronteiras nacionais, que proporcionam o estabelecimento de um mecanismo institucional para facilitar a cooperação entre seus membros nos campos da segurança, econômica, social ou afins. Desta maneira, as áreas de atuação das organizações internacionais variam de acordo com os seus objetivos, mas pode-se citar algumas principais, como política internacional, economia, diplomacia, políticas de segurança, resolução de conflitos, entre outras. A Convenção de Viena de 1986 buscou regulamentar as normas de direito internacional aplicáveis as organizações internacionais.

Eiiti Sato (2003, p. 164) afirma que:

As organizações internacionais são a expressão mais visível dos esforços de cooperação internacional de forma articulada e permanente. Desde o surgimento do Estado Nacional como categoria política central nas relações entre povos e unidades políticas, a história registra a ocorrência de iniciativas de estadistas e formulações de pensadores voltadas para a estruturação de instituições que hoje chamamos de organizações internacionais.

O multilateralismo surge através da necessidade de cooperação, o que de certa forma já representa um avanço nas relações entre Estados. Estabelece princípios gerais como não discriminação ou favorecimento de determinado Estado, indivisibilidade, ou seja, de aplicação dos acordos a todos os envolvidos e, ainda, o princípio da reciprocidade difusa, uma ampliação da ideia de troca mútua, tendo em vista a estabilização das relações entre esses atores (RAMOS, 2011, p. 15-16).

De acordo com Inis Claude (apud Ramos, 2011, p. 17), as organizações internacionais possuem quatro pré-requisitos para seu pleno desenvolvimento: a existência de Estados soberanos; um fluxo de contatos significativos entre eles; o reconhecimento pelos Estados dos problemas que surgem a partir de sua coexistência e da necessidade de criação de instituições e métodos sistemáticos para regular suas relações. 
Rozine de Abreu (2004, p. 4) aponta que as organizações internacionais podem ser divididas em três categorias:

(...) intergovernamentais, que são as criadas por acordos entre governos e cujos membros são os Estados; não governamentais, que não são criadas por acordos entre governos e cujos membros são grupos ou indivíduos e normalmente elas têm caráter consultivo junto às intergovernamentais; e transnacionais, que são dirigidas de forma centralizada por burocracias não governamentais, ultrapassam as fronteiras nacionais e não necessariamente apresentam caráter representativo - o que significa que não trabalham com demandas sociais. O melhor exemplo desta última categoria são as empresas multinacionais.

No que tange ao direito internacional, o termo organização internacional aplica-se apenas às organizações constituídas por Estados. Por outro lado, existem também as chamadas organizações não governamentais, que pertencem à sociedade civil e que, em certos casos, possuem atuação em âmbito internacional.

As organizações não governamentais (ONGs) referem-se, como o próprio nome diz, a organizações que não são nem governo, nem de qualquer empresa que possua governança com fins lucrativos. Sua definição faz parte do sistema de representação da ONU a partir da resolução 288 do Conselho Econômico e Social das Nações Unidas. São consideradas como grupos sociais organizados, sem fins lucrativos, constituídas formalmente e autonomamente. Suas atuações são caracterizadas por ações de solidariedade, ações humanitárias e pelo legítimo exercício de pressões políticas em nome de populações excluídas. Em geral, as organizações não governamentais que vêm surgindo tomam por base um discurso cosmopolita, cada uma dentro de sua área específica.

O Banco Mundial (1989) define ONGs como sendo “organizações privadas que exercem atividades para aliviar o sofrimento, promover os interesses dos pobres, proteger o meio ambiente, prestar serviços sociais básicos, ou se comprometer com o desenvolvimento da comunidade". Sherrer-Warren (1999, p. 31) define que:

Do ponto de vista formal [as ONGs] são agrupamentos coletivos com alguma institucionalidade, as quais se definem como entidades privadas com fins públicos e sem fins lucrativos e contando com alguma participação voluntária (engajamento não-remunerado, pelo menos do conseIho diretor). Portanto, distinguem-se do Estado/governo, do mercado/empresas e se identificam com a sociedade civil/associativismo. Nesse universo, incluem-se tanto organizações meramente recreativas ou de assistência social como as participantes ou atuantes nas políticas públicas e na politização do social.

Destaca Neera Chandhoke (2002) que o aumento significativo das chamadas organizações não governamentais (ONGs) e sua importância nessa chamada sociedade civil global. Outro aspecto importante diz respeito ao relativo poder que possuem, por vezes afetando a agenda política nacional e internacional, chamando a atenção para outros problemas, além de serem fortes formadoras de opinião pública.

As ONGs fazem parte do chamado Terceiro Setor, que é formado por todas as "organizações e iniciativas privadas dirigidas à produção de bens e serviços públicos" (Fer- 
nandes, 1995, p. 32). Pode-se apontar entidades filantrópicas e fundações privadas, cuja valorização do trabalho voluntário é uma das principais características (Pinto, 2006).

Por outro lado, visando fins lucrativos, empresas transnacionais aparecem também como atores importantes para se entender o fenômeno da governança global. São organizações que possuem um grupo, uma rede de empresas baseadas na produção de bens de controle ou serviços em um ou mais países - não apenas no seu país de origem. Seus limites ultrapassam territórios através da instalação de filiais em outros países. Embora operando em diversos países, normalmente seus principais diretores possuem uma estratégia de gestão geral, mas suas decisões principais baseiam-se em sua sede, sem qualquer influência de suas subsidiárias no exterior.

Diante do contexto da globalização, percebe-se que empresas transnacionais produzem partes de um produto em países distintos, com o objetivo de reduzir custos de produção. Estas empresas operam com uma estratégia abrangente, visando única e exclusivamente o lucro, para obter o máximo de benefícios, sem possuir caráter representativo social (Abreu, 2004, p. 4). Por exemplo, é comum que elas comprem matéria-prima em locais mais baratos, instalando suas filiais nos locais mais vantajosos - com mão de obra barata - ao redor do mundo, tendo em vista vender os seus produtos em escala global. Portanto, essas empresas possuem uma influência não só no campo econômico, como em campo político, pois elas interferem em governos e em relações entre países.

\section{Atores não estatais, mecanismos alternativos e rearticulações: sociedade civil global e democracia cosmopolita}

Diante disso, os desafios do pensamento contemporâneo das Relações Internacionais exigem uma compreensão atual do papel do Estado na esfera internacional e as novas modalidades de organização política. Então, a análise dessa problemática passa, necessariamente, por uma nova compreensão do conceito de soberania. Acordos, contratos, coerções e imposições são, para Krasner, o principal meio pelo qual a soberania westfaliana é corroída. As convenções ou convenções internacionais ignoram os contratos porque a reciprocidade não é essencial.

Esses acordos, quando reconhecem a possibilidade de submeter certas práticas internas à supervisão externa, "convidam os atores externos a exercer alguma influência sobre as estruturas de autoridade interna". Tendo em conta essa concepção fluida e instável da soberania, Krasner conclui que a ordem internacional é um dos sistemas mais debilitados institucionalmente, onde por falta de uma "estrutura de autoridade hierárquica bem estabelecida, coerção e imposição são constituídas em opções que o forte sempre pode usar contra os fracos" (Rivero Garcia, 2003, p. 211-212).

Precisamente, para combater os efeitos perversos desse sistema, David Held (1995) formulou sua proposta de um direito democrático cosmopolita, o qual propõe a mudança da realidade, diante da manutenção da desigualdade e hierarquia que existe no sistema. A proposta prevê a criação de mecanismos democráticos que complementem as esferas nacional, regional, global. Possui um papel de destaque crescente na sociedade internacional. A democracia cosmopolita tem um propósito político através de interações globais, com base em princípios igualitários de justiça e participação política (Held; McGrew, 2003, p.106-107). 
Nesse sentido, Montiel (2005, p. 31) afirma:

Finalmente, una agenda para la era global se hace indispensable, que sea capaz de: garantizar un suministro adecuado de bienes públicos globales; superar gradualmente las asimetrías de carácter global y construir una agenda social internacional basada en los derechos; desarrollar instituciones globales respetuosas de la diversidad; buscar una complementariedad virtuosa entre desarrollo institucional global, regional y nacional; provocar una participación equitativa de los países en desarrollo y reglas adecuadas de gobernabilidad. Las estrategias nacionales ante la globalización en un ámbito de pactos sociales sólidos y democráticos, deben incluir por los menos cuatro elementos: políticas macroeconómicas que facilite la inversión productiva y disminuya la vulnerabilidad macroeconómica. El desarrollo de una competitividad sistémica; el reconocimiento de una agenda ambiental como prioridad; y políticas sociales dinámicas en materia de empleo, educación y protección social.

A globalização, ao não evoluir democraticamente, não traz resultados equitativos tampouco promove o bem comum. Em razão disso, existe a necessidade de aprofundar uma democracia a nível global. Com relação às questões econômicas, para que haja condições de uma governança é essencial estabelecer uma política para a economia e uma economia para a democracia.

Deve haver espaço para a participação da sociedade civil e organizações nãogovernamentais na tomada de decisões para a formulação e implementação de políticas públicas. O Progressismo Transnacional elabora a consciência e a formação de uma Sociedade Civil Global, com base política e social, e de "legitimidade" da Governança Global.

\section{Considerações Finais}

A delimitação temporal da pesquisa se deu a partir da década de 1990, devido à ascensão dos processos de globalização após a guerra fria, da nova ordem multipolar e do recrudescimento do neoliberalismo. Ocorreu assim mudanças nos paradigmas internacionais das relações políticas e econômicas entre atores heterogêneos e plurais - Estados nacionais, empresas multinacionais, sociedade civil global, organizações internacionais, blocos regionais. Isso ampliou os cenários e espaços de disputa pelo poder. O caráter contraditório e por vezes não explícito da governança global tem apresentado desafios teóricos para qualquer tentativa de entender seu funcionamento e sua evolução.

As estruturas globais contemporâneas possuem duas tendências: a emergência de desafios globais e o surgimento de potências não tradicionais. Em razão disso, há implicações na compreensão da ordem, justiça, desigualdade, ação coletiva e das normas e instituições globais. As conhecidas estruturas de governança global (ex: Conselho de Segurança da ONU, o G8) enfrentam o desafio de entender as novas influências.

Há, portanto, uma disputa no âmbito da governança na economia e na política global contemporânea, sendo cada vez mais caracterizada pela transnacionalização de práticas, discursos e agendas. O que também se observa nessa multiplicidade de atores são o modo de atuação, muitas através de regulamentação intergovernamental e, outras, na forma de autoridade privada e autorregulada. A emergência destas novas estruturas, 
muitas vezes interagindo o público e o privado, levou Robert Cox à ideia de que estamos diante de uma governança global nebulosa em andamento.

A análise feita compreende a governança global no contexto neoliberal, amparada pelos imperativos do capital em escala mundial. Os requisitos da liberdade global na disputa e na relação entre uma multiplicidade de atores com naturezas distintas em termos representativos, são compostos pelo movimento do capital que influencia a forma de governança global sem necessariamente um governo autorizado pelas populações nacionais. O conceito, usado por vezes de forma literal, sofreu o mesmo destino de outros conceitos normativos como "responsabilidade social" ou "desenvolvimento sustentável", tendo sido cooptado por forças hegemônicas do sistema internacional.

Diante disso, há a necessidade de mecanismos alternativos nesse cenário de disputa de poder. Nesse sentido, há a preocupação de que haja uma governança democrática inclusiva, como Held denomina, uma democracia cosmopolita. Deve ter como um dos seus eixos centrais, a participação cidadã, através da sociedade civil global, através de um progressismo transnacional para resolver problemas públicos globais, regionais e locais.

\section{Referências}

Abreu, R. A. M. (2004). Conceito de Governança Global: Problema da Reforma das Nações Unidas. Disponível em

http://www.ronizealine.eti.br/download/conceitodegovernancaglobal.pdf (Acesso em: 17/07/2017)

Avritzer, L. (2002). Globalização e espaços públicos: a não regulação como estratégia de hegemonia global. Revista Crítica de Ciências Sociais, 63, 107-121.

Banco Mundial (1989). Diretiva Operacional 14.70. Involving Nongovernmental Organizations in World Bank-Supported Activities. Disponível em http://www.gdrc.org/ngo/wb-ngo-directive.html (Acesso em: 17/07/2017)

Ballestrin, L. M. A. (2010). Com quantas armas se faz uma sociedade "civil”? Controles sobre armas de fogo no Brasil, Portugal e Governança Global (1995-2010). Tese de Doutorado, Ciência Política/Universidade Federal de Minas Gerais.

Brunkhorst, H. (2011). Alguns problemas conceituais do cosmopolitismo global. Revista Brasileira de Ciências Sociais, vol.26, n.76.

Cardozo de da Silva, E. (2007). Teoría de las Relaciones Internacionales y Soberanía: Construcción, Desconstrucción y Reconstrucción. Cuadernos Unimetanos, Universidad Metropolitana, Decanato de Investigaciones y Desarrollo, Caracas-Venezuela, Año II, no 11, p. 180-191.

Chandhoke, N. (2002). The limits of global civil society. In: Yearbook Global Civil Society, LSE. Comissão Sobre Governança Global (1996). Nossa Comunidade Global. Rio de Janeiro: Editora FVG.

Fernandes, R. C. (1995). Elos de uma Cidadania Planetária. Revista Brasileira de Ciências Sociais. São Paulo, №28.

Held, D. (1995). Democracy and the Global Order: from the modern state to cosmopolitan 
Governança global: visões teóricas e pluralidade de atores - (107- 120)

governance. Stanford: California.

Herz, M. e Hoffmann, A. (2004). Organizações Internacionais - história e práticas. Rio de Janeiro: Ed. Campus.

Jenks, B. (2015). Cooperación para el desarrollo de las Naciones Unidas Las raíces de una agenda de reforma. In: Ocampo, J. A. (editor). Gobernanza global y desarrollo: Nuevos desafíos y prioridades de la cooperación internacional-1aㅡ ed.- Buenos Aires: Siglo Veintiuno

Koenig-Archibugi, M. (2003). Mapping global governance. Workshop 11 - The Governance of Global Issues: Effectiveness, Accountability, and Constitutionalization.

Krasner, Stephen D. (1999). Sovereignty. Organized Hypocrisy. Princeton: Princeton University Press

Lupel, A. (2003). Democratic Politics and Global Governance: Three Models. Disponível em: http://web.iaincirebon.ac.id/ebook/moon/democracy/Lupel 11-20-03.pdf (Acesso em: 17/07/2017)

Marques, M. C. C. (2007). Aplicação dos princípios da governança corporativa ao sector público. Revista de Administração Contemporânea. Curitiba, v. 11, n. 2, p. 11-26.

Montiel, L. E. C. (2005). Globalización, democracia y gobernanza global: perspectiva latinoamericana (Universidad Autónoma De Baja California). VII Congreso Español de Ciencia Política y de la Administración. Democracia y Buen Gobierno.

Morgenthau, H. J. (2003). A política entre as nações. A luta pelo poder e pela paz. Brasília: Editora UnB, 2003.

Pinto, C. R. J. (2006). As ONGs e a política no Brasil: presença de novos atores. Dados. Rio de Janeiro, v. 49, n. 3, p. 651-670.

Ramos, P. O. (2011). Por que a Fifa funciona? - Uma análise da organização internacional que controla o futebol no mundo. Trabalho de Conclusão de Curso. Especialização em Relações Internacionais/Universidade de Brasília.

Rivera García, A. (2003). Crisis internacional de la soberanía y modelo cosmopolita de democracia. (A propósito de Stephen D. Krasner: Soberanía, hipocresía organizada, Tr. Ignacio Hierro,). Araucaria, 9, 209-213.

Rosenau, J. (2000). Governança, ordem e transformação na política mundial. IN: Governança sem governo: ordem e transformação na política mundial. Brasília: Editora da Universidade de Brasília.

Santos, B. S. (2002). Os processos da Globalização. Revista Crítica de Ciências Sociais. Disponível em: http://www.eurozine.com/articles/2002-08-22-santos-pt.html (Acesso em: 17/07/2017)

Santos, M. H. C. (1997). Governabilidade, Governança e Democracia: Criação de Capacidade Governativa e Relações Executivo - Legislativo no Brasil Pós - Constituinte. Vol. 40, n. 3, Rio de Janeiro. Disponível em: http://www.scielo.br/scielo.php?pid=S001152581997000300003\&script=sci a rttext\& tlng=es (Acesso em: 18/07/2017) 
Sato, E. (2003). Conflito e cooperação nas relações internacionais: as organizações internacionais no século XXI. Revista Brasileira de Política Internacional. Vol. 46, № 02, p. 161-176.

Scherrer-Warren, I. (1999). Cidadania sem fronteiras: ações coletivas na era da globalização. São Paulo: Hucitec.

Villa, R. D. (2001). A construção de um sistema internacional policêntrico: atores estatais e não-estatais societais no pós-Guerra Fria. Revista Cena Internacional. Vol. 03, № 02, p. 65-87. Disponível em:

http://www.mundorama.info/Mundorama/Cena Internacional files/Cena 20 01 2.pdf (Acesso em: 20/07/2017)

Villa, R. D. e Tostes, A. P. (2006). Democracia cosmopolita versus Política Internacional. Lua Nova Revista de Cultura e Política, São Paulo, n. 66. 